\title{
Electrochemical Behavior of Steel-FeNbC Composites Used in the Production of Oxygen
}

\author{
Ariadne de Souza Silva*, Antonio Eduardo Martinelli, Hélio Scatena Júnior, \\ Jorge Herbert Echude Silva, Clodomiro Alves Júnior, Michele Portela Távora \\ Programa de Doutorado em Ciências e Engenharia de Materiais, PDCEM \\ Universidade Federal do Rio Grande do Norte, 59078-970 Natal - RN, Brazil
}

Received: November 23, 2003; Revised: February 3, 2005

\begin{abstract}
The electrocatalytic properties of steel-FeNbC composites were evaluated after potentiostatic ageing with the purpose of establishing the potential use of such materials as electrodes for the industrial production of oxygen. The effect of processing parameters, involved in the production of the composites by powder metallurgy, such as milling conditions and compaction pressure, on the performance of the electrodes was also studied. The electrodes were characterized according to their electrical resistance in $\mathrm{NaOH} 1 \mathrm{M}$ solution, considering that the purpose of the application requires this value to be $\sim 0.5 \Omega . \mathrm{cm}^{2}$. This parameter was evaluated from repetitive electrochemical measurements carried out from $0.7 \mathrm{~V}$ to $1.5 \mathrm{~V}$ ( $v s$. $\mathrm{Ag} / \mathrm{AgCl}$ ) by electrode anodization. Changes in the electrochemical behavior of the electrodes, especially concerning the $\mathrm{O}_{2}$ evolution in alkaline medium, were studied as a function of the applied potential. The results revealed that the electrocatalytic activity of the electrodes increased upon ageing, probably as a consequence of the growth of oxide layers and/or increase in the conductivity of the material, resulting in current gain and corresponding decrease in the polarization resistance to $0.75 \Omega \mathrm{cm}^{2}$.
\end{abstract}

Keywords: metal-ceramic composites, niobium carbide, oxygen evolution, electrochemistry

\section{Introduction}

The evolution of oxygen involves demanding chemical reactions, which are highly sensitive to the nature and structure of the electrocatalyst. Such reactions are the basis for different processes including anodic protection and electroorganic oxidation ${ }^{1-3}$. The selection of appropriate anode materials is an important step in the optimization and economical appraisal of oxygen evolution reactions. The performance of electrocatalysts is frequently monitored by estimating the rate of current variation as a function of overpotential, which is numerically equal to the slope in the $\eta v s$. current density plot. Materials of interest are cost-efficient and exhibit high electrochemical efficiency along with stability in typical electrochemical reaction environments. Novel materials have been studied to fulfill such demands, including systems based on mixtures of metallic oxides, especially transition metals oxides ${ }^{3-5}$.

The electrocatalytic activity of transition metal oxide electrodes has been attributed to surface redox reactions taking place where metallic ions act as active sites. These redox centers are capable of catalyzing a variety of reactions that occur at the electrode and at potentials close to that of the redox couple. This scenario implies a general mechanism for the main electrolytic reactions, including oxygen evolution, for which the surface is initially oxidized. Subsequently, the active sites interact with reagents such as $\mathrm{H}_{2} \mathrm{O}$ or $\mathrm{OH}^{-}$, producing $\mathrm{O}_{2}{ }^{5}$.

Surface oxide layers can be obtained anodically using potentiostatic or galvanostatic methods. Their thickness can be adjusted by subsequent application of potential cycles for long periods of time or complex sequences of periodic potentials. The morphology and structure of electrolytic oxides are significantly different from those of thermal oxides deposited onto inert supports, as in the case of DSA ${ }^{\circledR}$ electrodes, in that anodic oxides are hydrated. The stability, composition, and thickness of anodically grown oxide layers depend on the nature of the electrolytic solution and its $\mathrm{pH}^{9}$. For industrial applications, alkaline environments are preferred, since they allow better corrosion control and, consequently, the use of inexpensive materials as compared to acid processes. A number of compounds and associated composites possess high chemical stability in alkaline solutions during the $\mathrm{O}_{2}$ evolution ${ }^{4}$.

The objective of this investigation was to evaluate the potential application of steel-FeNbC electrodes as well as changes in its polarization resistance that result from potentiostatic ageing. Anodization of these electrodes intensifies its electrocatalytic activity due to growth of porous oxide layers and increased conductivity. Composite samples were prepared by powder metallurgy in which the milling, pressing and sintering conditions were varied and their effects evaluated by electrochemical and microstructural analyses. Correlations between microstructural properties and electrochemical activity were made with the objective of optimizing process parameters for this specific application.

\section{Experimental Procedures}

Composite (Fe,C) - 10 wt. (\%) FeNbC samples were sintered in a resistance furnace at $1200{ }^{\circ} \mathrm{C} / \mathrm{h}$ and then used to manufacture electrodes for the production of $\mathrm{O}_{2}$. Seven sets of samples were sintered and classified according to milling and pressing conditions, as well as final density, as summarized in Table 1.

Electrochemical analyses were carried out using a three-electrode system, i.e., a working electrode, a reference $\mathrm{Ag} / \mathrm{AgCl}$ electrode, and a platinum counter-electrode with a large surface area. The electrochemical cell was made of glass and contained four cylindrical tubes. The central cylinder housed the working electrode. The volume of $1 \mathrm{M} \mathrm{NaOH}$ solution was $300 \mathrm{~cm}^{3}$ and the system permitted continuous 
bubbling of oxygen. An EG\&G 273 A potentiostat was used to record the kinetic parameters related to electrode characterization. Electrochemical evaluation was carried out by scanning the potential from 0.7 to $1.5 \mathrm{~V}$ in steps of $50 \mathrm{mV}$ and at time intervals of 100 seconds between consecutive potentials. All the potentials are with respect to the $\mathrm{Ag} / \mathrm{AgCl}$ electrode immersed in $1 \mathrm{M} \mathrm{NaOH}$ solution. The values of electrical resistance in the solution were estimated from the slope of the linear plot of applied potential as a function of the current measured in the last scan of each electrode. The microstructures resulting from the ageing process were examined using a Philips XL30 ESEM scanning electron microscope (SEM).

\section{Results and Discussions}

The electrical resistances of the composite electrodes immersed in $1 \mathrm{M} \mathrm{NaOH}$ solution are summarized in Table 2. They are representative of the electrochemical behavior of the electrodes during $\mathrm{O}_{2}$ evolution and the anodically formed surface oxide layers. Metallic oxides used in electrocatalysis are the interfaces where reactions take place. Their main role is to enable electrogeneration of products, such as $\mathrm{O}_{2}$, at relatively low applied overpotentials, thus improving the cost-efficiency of the process ${ }^{1}$. The electrodes tested in this study revealed a gradual increase in current values upon potentiostatic ageing. This behavior could be attributed to the formation of anodic oxide layers and their porous nature, which contribute to higher conductivity that results from increased specific area. This effect was observed from the decrease in polarization resistance of the electrodes. Interesting results were obtained when the electrocatalytic response of the electrodes was determined after each ageing cycle. A plot of applied potential versus final current values of all samples is shown in Figure 1.

The microstructures of some aged electrodes are shown in Figures 2-4. It is possible to observe that the specific area increased as the electrodes were aged. The ageing process etched the surfaces of the electrodes. A significant number of flaws and pores were formed and these increased the specific surface area of the electrodes. Exami-

Table 1. Process parameters and apparent density of composite ( $\mathrm{Fe}, \mathrm{C})-\mathrm{FeNbC}$ samples.

\begin{tabular}{lcccc}
\hline $\begin{array}{l}\text { Sample } \\
\text { Identification }\end{array}$ & $\begin{array}{c}\text { Milling time } \\
\text { and speed } \\
(\mathrm{h} / \mathrm{rpm})\end{array}$ & $\begin{array}{c}\text { Compaction } \\
\text { Pressure } \\
(\mathrm{MPa})\end{array}$ & $\begin{array}{c}\text { Apparent } \\
\text { Density } \\
\mathrm{g} / \mathrm{cm}^{3}\end{array}$ & $\begin{array}{c}\text { Sintering } \\
\text { Temperature } \\
\left({ }^{\circ} \mathrm{C}\right)\end{array}$ \\
\hline Electrode 1 & $10 \times 150$ & 500 & 6.05 & 1200 \\
Electrode 2 & $20 \times 150$ & 400 & 6.10 & 1200 \\
Electrode 3 & $20 \times 150$ & 500 & 6.20 & 1200 \\
Electrode 4 & $10 \times 300$ & 500 & 6.50 & 1200 \\
Electrode 5 & $15 \times 225$ & 300 & 6.60 & 1200 \\
Electrode 6 & $15 \times 225$ & 400 & 6.89 & 1200 \\
Electrode 7 & $15 \times 225$ & 500 & 7.20 & 1200 \\
\hline
\end{tabular}

Table 2. Electrical resistance of composite electrodes in $1 \mathrm{M} \mathrm{NaOH}$ solution.

\begin{tabular}{lc}
\hline Sample Identification & $\begin{array}{c}\text { Electrical resistance } \\
\text { in solution } \Omega . \mathrm{cm}^{2}\end{array}$ \\
\hline Electrode 1 & $0.75 \pm 0.01$ \\
Electrode 2 & $0.95 \pm 0.03$ \\
Electrode 3 & $1.07 \pm 0.01$ \\
Electrode 4 & $0.95 \pm 0.01$ \\
Electrode 5 & $1.21 \pm 0.04$ \\
Electrode 6 & $1.40 \pm 0.02$ \\
Electrode 7 & $0.76 \pm 0.03$ \\
\hline
\end{tabular}

nation of Figure 4 reveals that ageing of electrodes 2 and 3 resulted in distinct topographical features, suggesting a close correlation between process parameters, such as density and electrochemical activity. Lower density resulted in extensive damage to the surface, and larger pores, compared to denser materials. In general terms, porous samples present better electrocatalytic behavior, since elec-

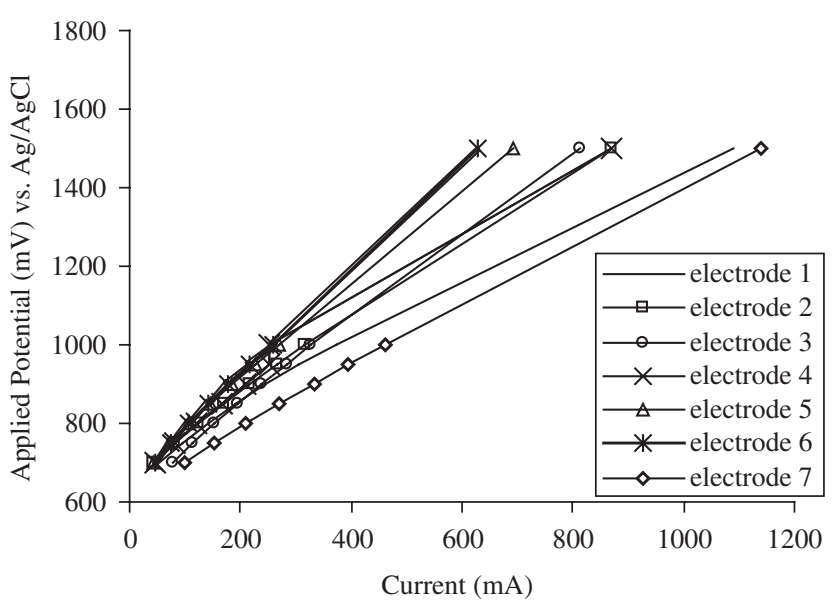

Figure 1. Plot of applied potential vs. current of aged composite electrodes.

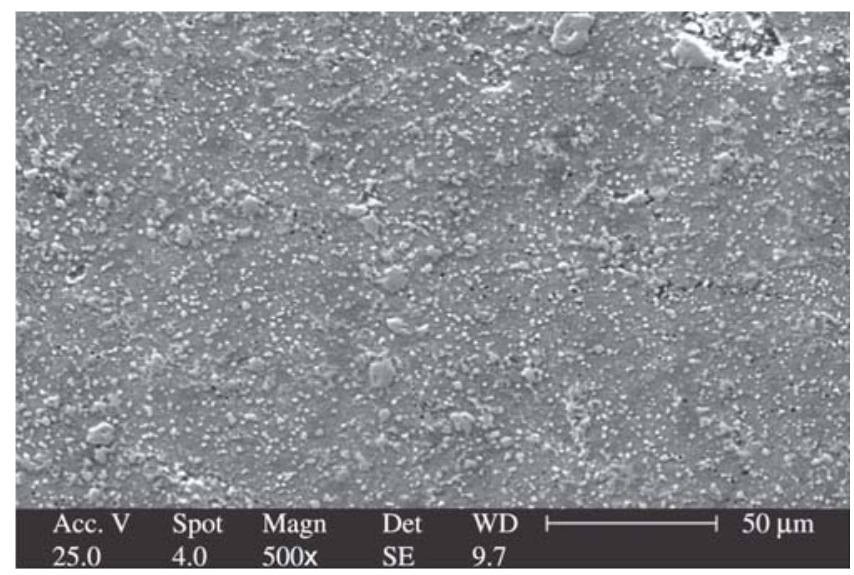

(a)

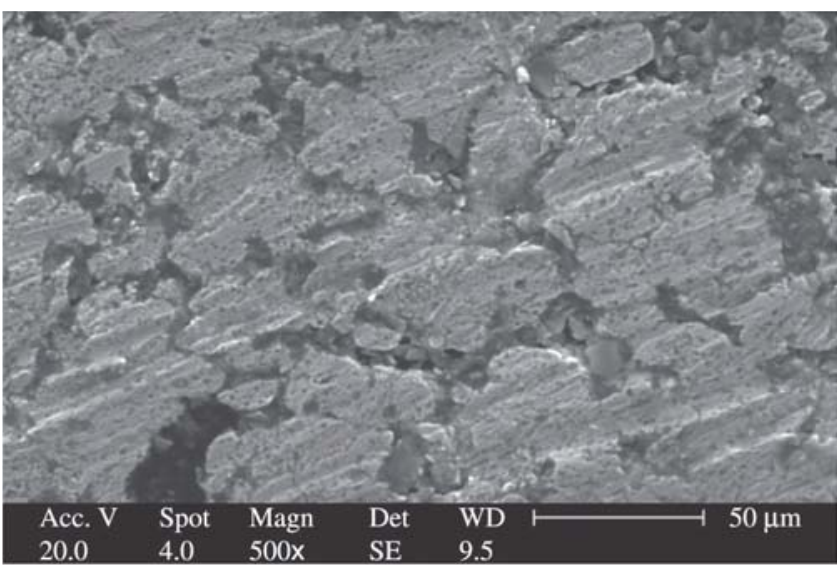

(b)

Figure 2. Scanning electron micrographs of electrode 1: a) before; b) after potentiostatic ageing. 


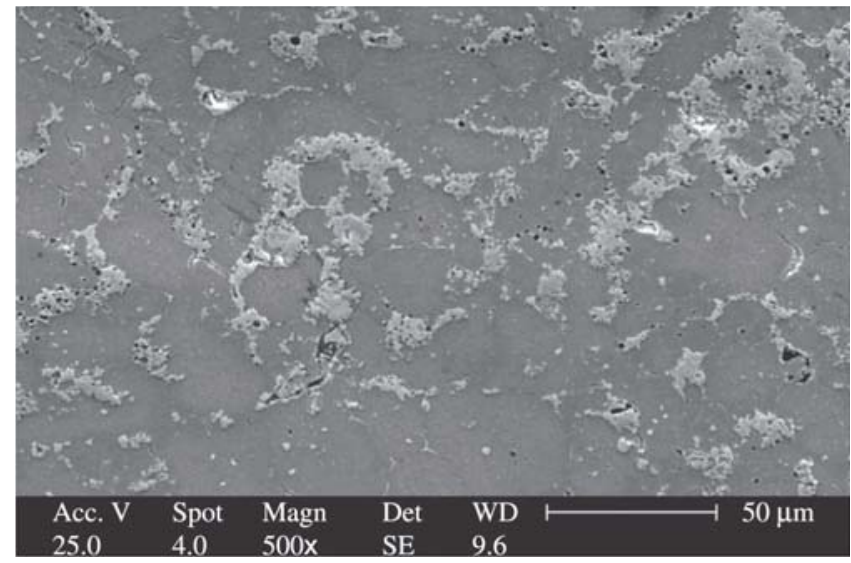

(a)

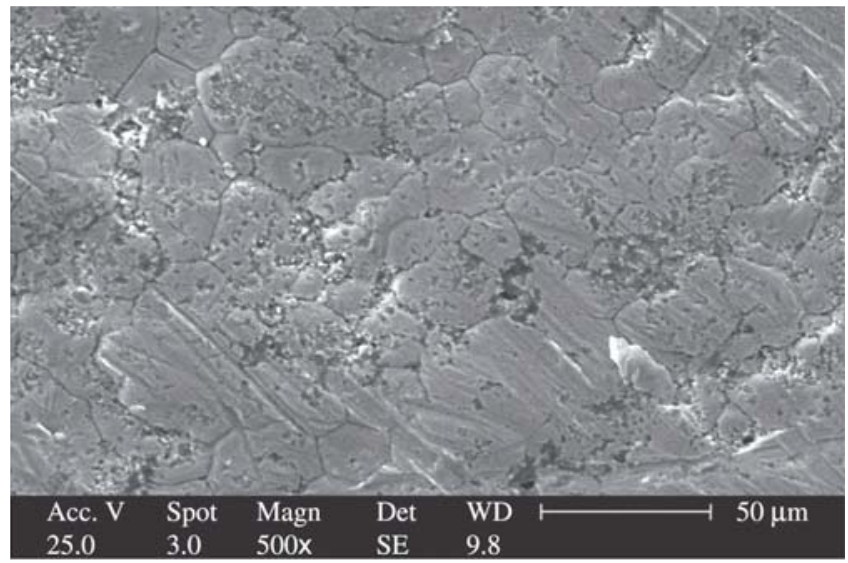

(b)

Figure 3. Scanning electron micrographs of electrode 7: a) before; b) after potentiostatic ageing.

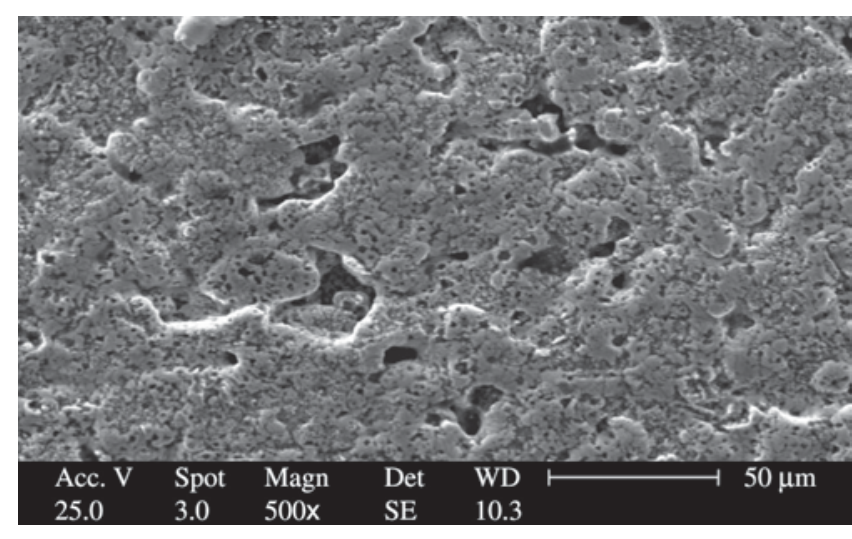

(a)

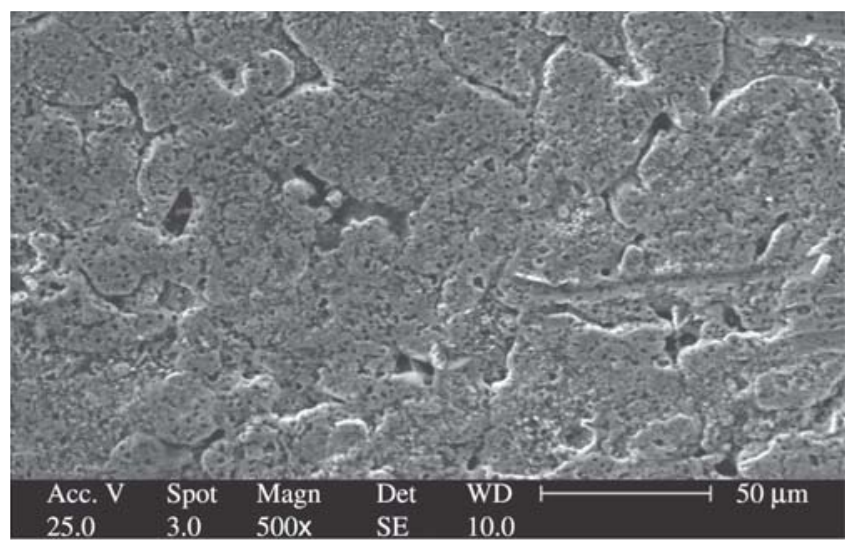

(b)

Figure 4. Scanning electron micrographs of potentiostatically aged electrodes: a) 2; b) 3 .

troactive species, such as $\mathrm{OH}$, easily react with the transition metal ions upon oxidation of the surface. However the results presented in Table 1 clearly indicate that it is not possible to establish a simple correlation between density and polarization resistance, since other microstructural aspects also influence the electrochemical behavior of the composite electrodes, including pore and reinforcing particle shape, size and distribution. Further studies are under way to clarify these aspects. Previous results also indicated that the composite was a promising material in terms of electrode activity, due probably to the synergestic effects caused by the addition of carbide particles, similar to that commonly observed in oxide mixtures ${ }^{7}$.

\section{Conclusions}

The electrical resistance of electrodes in aqueous solution, or polarization resistance, is an important parameter to help define the applicability of new electrode materials for the production of industrial gases. Polarization resistance values as low as $0.75 \Omega . \mathrm{cm}^{2}$ were obtained for this new class of materials. Ageing the composite electrodes affected the polarization resistance of the material as a consequence of the porous microstructure of the surface oxide layer formed in the process. Processing parameters and microstructural features, such as density and distribution of pores and reinforcing particles, apparently play a role in determining the polarization resistance of relatively low-density composite electrodes.

\section{Acknowledgments}

The authors thank the National Research Council of Brazil, $\mathrm{CNPq}$, for granting a doctorate scholarship to carry out this research investigation.

\section{References}

1. Trasatti S. Physical electrochemistry of ceramic oxides. Electrochimica Acta. 1991; 36(2):225-241.

2. Trasatti S. Electrocatalysis in the anodic evolution of oxygen and chlorine. Electrochimica Acta. 1984; 29(11):1503-1512.

3. Bocca C, Gerisola G, Magnone E, Barbucci A. Oxygen evolution on $\mathrm{Co}_{3} \mathrm{O}_{4}$ and $\mathrm{Li}$-doped $\mathrm{Co}_{3} \mathrm{O}_{4}$ coated electrodes in an alkaline solution. International Journal of Hydrogen Energy. 1999; 24(8):699-707.

4. Fazle Kibria AKM, Tarafdar SA. Electrochemical studies of a nickelcopper electrode for the oxygen evolution reaction (OER). International Journal of Hydrogen Energy. 2002; 27(9):879-884.

5. Trasatti S. Electrocatalysis: understanding the success of DSA@.Electrochimica Acta. 2000; 45(15-16):2377-2385.

6. Oliveira EM, Marino CEB, Biaggio SR, Rocha Filho, RC. Reactivation of passive titanium: the enhancement of $\mathrm{O}_{2}$ evolution after potentiodynamic cyclings. Electrochemistry Communications. 2000; 2(4):254-258.

7. Silva AS, Scatena JrH, Martinelli AE, Alves JrC. Electrochemical characterization of niobium carbide reinforced composites for the production of industrial gases. Materials Science Forum. 2003; 416-418:60-63. 